publishing the proceedings of what were evidently, within their respective frameworks, interesting and illuminating meetings.

P. L. KROHN

\section{MUSIC AND PHYSICS}

\section{The Physics of Musical Sounds}

By C. A. Taylor. (Applied Physics Guides.) Pp. xii + $196+$ record. (London: The English Universities Press, Ltd., 1965.) 42s. $6 d$.

Music is important to many of us, and sound is important to all but the deaf. Yet, as Prof. Taylor writes concerning his experience with budding physicists, "sound had been missed out and the problem of teaching it at a higher level became more challenging".

This book can serve for a useful undergraduate course in physies with an emphasis on sound and music. It contains neat, self-contained treatments of the wave equation, the vibration of strings, square membranes, and cylindrical and conical pipes, harmonic analysis, Fourier transforms, convolution, resonance, coupled systems and starting transients. Mathematical sections are indicated by an asterisk at the heading, so that the musician can skip them in reading the book. The purpose and general nature of the mathematics is clearly explained in the rest of the text.

On the musical side there are wise, if necessarily incomplote discussions of the nature of musical sound, hearing, sum and difference tones, scales, consonance and dissonance, and architectural acoustics. The theme of "the possibility of designing a completely new musical instrument" unifies the musical and the physical content of the book.

The book seems quite reliable. On page 39 it says "It is thus clear that the ear is insensitive to phase . . ." which contradicts some experimental results for steady tones ${ }^{1}$ but conforms to traditional experiments. As Prof. Taylor notes in many places, our knowledge of acoustics, and especially of psychoacoustics and physiological acoustics, is small.

Wo may hope that the publication of The Physics of Musical Sounds will help to overcome tho present neglect of acoustics. Other influences are at work. Advances in electronic instrumentation, and especially in digital computers, have given to-day's acousticians much more flexible and powerful tools than the ingenious optical and mechanical techniques on which Prof. Taylor dwells. Concerning experiment, the book is a good summing-up of what has gone before, and a useful source of references for musicians and physicists alike. But to-day techniques which are merely mentioned are pushing our knowledge of acousties forward.

J. R. Pierce

${ }^{1}$ J. Acoustical Soc. Amer., 31, 1579 (1959).

\section{TRAFFIC CONTROL}

\section{Traffic Control}

Theory and Instrumentation. Edited by Thomas R. Horton. (Based on papers presented at tho Interdiscip. linary Clinic on Instrumentation Requirements for Traffic Control Systems, held December 16-17, 1963, at New York City.) Pp. xi +218 . (New York: Plenum Press, 1965.) 12.50 dollars.

THIs book contains ten papers divided into two sections, "Traffic Control Instrumentation, Theory and Practice" and "Case Studies of Large-scale Integrated Traffic Control Systems", and provides a useful summary of American work on road traffic control, from both the theoretical and the practical point of view. It contains a very roadable introduction and a useful short list of publications for the reader who wishes to go further. Most of the information has been published elsewhere, but it is very useful to have it collected in a single volume. The information on instruments is not too detailed, but is sufficient to show the principles of operation of devices for measuring the basic quantities required for control.

The fundamental relations between the three variables, flow, concentration and speed, are discussed in one paper, although no reference is made to the basic work of Lighthill and Whitham ${ }^{1}$ in this field. Several theoretical models give relations between speed and concentration which are fairly close to observed results over most of the range, although they all tend to be unrealistic to a greater or lesser extent at low concentrations.

In order to design a traffic control scheme, one needs a judicious blend of theoretical analysis and practical engineering ability. On the whole the book brings out the need for both, although the relationship between them may not always seem clear. A theoretical approach which includes a large empirical element appears to have been the most successful one. The paper by D. L. Gerlough on simulation of traffic situations, using digital electronic computers, rightly points out that comparatively rough models can be adequate for making the required calculations. In most cases what is required is the effect on the overall travel time of a change in the control system. Travel time can be very susceptible to small changes in the flow of traffic, the types of vehicles, the presence of parked vehicles and a large number of other factors, not all of which can be fully controlled. It may seem to be desirable to allow precisely for all these effects, averaging out over the whole spectrum, but in practice it is sufficient to assume that conditions are uniform, at any rate during normal working hours. Conditions during peak periods are special and the traffic demand may be changing rapidly. Intersections in particular are frequently overloaded during peak hours and mothods of minimizing delay under these conditions are discussed in an interesting paper by D. C. Gazis.

There is at present a great deal of interest in the central control of traffic signals by computer-two major schemes are being put in hand in West London and Glasgow. Methods of tackling such situations are given, and the experiment in Toronto, which was begun several years ago, is described with useful details of costs.

Some recent work at the Road Research Laboratory, using a computer programme which approximately minimizes total travel time in a network of signals, has been deseribed by Hillier ${ }^{2}$.

Another topic discussed is the control system for the Congress Expressway (an urban motorway) in Chicago. In this system congestion on the expressway at critical times is avoided by restricting the flow of traffic entering on a particular ramp. Assessment of the scheme has included measurements of the effects on traffic which finds an alternative route, and showed that during the whole peak period there was an average small reduction $(2 \cdot 5$ per cent) in travel time.

'Lighthill, M. J., and Whitham, G. B., Proc. Roy. Soc., A, 229, 317 (1955). "Hillier, J. A., Traffic Engineering and Control, 7, (8, 9), 502, 569 (1965).

\section{SUNDIALS REVIVED}

\section{Les Cadrans Solaires}

By R. R. J. Rohr. Pp. 208+4 colour plates. (Paris: Gauthier-Villars et Cie., 1965.) 58 F.

Iv the preface to this book, Dr. Henri Michel, of the Academie Internationale de l'Histoire des Sciences, cites three essentials of a good book: to have something to say; to say it; and to say nothing else. These are well realized in Captain Rohr's treatment of his subject, the sundial in all its forms. Beyond this, he achieves a remarkable blend of the philosophical, historical, artistic and practical, thus appealing to a wide range of readers. 